\title{
High prevalence of low bone mineral density in patients within 10 years of onset of ankylosing spondylitis: a systematic review
}

\author{
M. A. C. van der Weijden • T. A. M. Claushuis • \\ T. Nazari • W. F. Lems • B. A. C. Dijkmans • \\ I. E. van der Horst-Bruinsma
}

Received: 25 February 2012 /Revised: 28 May 2012 / Accepted: 30 May 2012 /Published online: 16 June 2012

(C) The Author(s) 2012. This article is published with open access at Springerlink.com

\begin{abstract}
Ankylosing spondylitis (AS) is a chronic inflammatory rheumatic disease. Decreased bone mineral density (BMD) is a common complication of AS, with a prevalence range of 19 to $62 \%$. Many studies have shown decreased BMD in AS with long disease duration, but only a few studies investigated BMD in early AS. The prevalence of decreased BMD in early disease stages of AS has not yet been clearly described, and for that reason, we reviewed the literature which describes the prevalence of decreased BMD in AS patients with a short disease duration $(<10$ years $)$. In this review, we included articles which used the modified New York criteria for the diagnosis of AS, included patients with a disease duration of less than 10 years, and used the WHO criteria for osteopenia and osteoporosis. Decreased BMD was defined as a $T$ score $<-1.0$, including both osteopenia and osteoporosis. For this review, only articles that acquired BMD data of lumbar spine and femoral neck by DXA were used. The literature search provided us 35 articles of which 7 matched all our criteria, and they will be further outlined in this review. The overall prevalence of decreased BMD of the articles reviewed is $54 \%(n=229 / 424)$ for lumbar spine and $51 \%(n=224 / 443)$ for femoral neck. The prevalence of osteopenia vs. osteoporosis for lumbar spine is $39 \mathrm{vs.} 16 \%$ and for femoral neck, 38 vs. $13 \%$. This review showed a high total prevalence of $51-54 \%$ decreased BMD and 13-16\%
\end{abstract}

M. A. C. van der Weijden $(\bowtie) \cdot$ T. A. M. Claushuis $\cdot$ T. Nazari

W. F. Lems · B. A. C. Dijkmans · I. E. van der Horst-Bruinsma Department of Rheumatology, VU University Medical Center, Room 3A-64, P.O. Box 7057, 1007 MB Amsterdam,

The Netherlands

e-mail: mac.vanderweijden@vumc.nl

W. F. Lems • B. A. C. Dijkmans

Reade, Department of Rheumatology,

Amsterdam, The Netherlands osteoporosis in AS with a short disease duration. This high prevalence was not to be expected in a relatively young and predominantly male population. Further research is needed to determine the clinical relevance of this low BMD by investigating the relation between low BMD and vertebral and nonvertebral fractures at this early stage in AS.

Keywords Ankylosing spondylitis · Bone mineral density · Osteopenia $\cdot$ Osteoporosis $\cdot$ Vertebral fractures

\begin{tabular}{ll}
\multicolumn{2}{l}{ Abbreviations } \\
AS & Ankylosing spondylitis \\
BMD & Bone mineral density \\
DMARDs & Disease-modifying antirheumatic drugs \\
DXA & Dual x-ray absorptiometry \\
NSAIDs & Nonsteroidal anti-inflammatory drugs \\
SD & Standard deviation \\
SpA & Spondylarthropathy \\
WHO & World Health Organization
\end{tabular}

\section{Introduction}

Ankylosing spondylitis (AS) is a chronic inflammatory rheumatic disease of the axial skeleton, which is characterized by low back pain and stiffness for more than 3 months that improves with exercise, but is not relieved by rest. Other important symptoms are restriction of motion of lumbar spine and limitation of chest expansion. Typical radiological features of AS are sacroiliitis on X-ray and bridging syndesmophytes of the spine, which usually take many years to develop, and besides that, not all AS patients develop these syndesmophytes. The first symptoms usually arise at an age younger than 30 years. Men are more often affected than women, and 
$90-95 \%$ of the AS patients are HLA-B27 positive. The prevalence of AS ranges between 0.1 and $1.4 \%$ in Europe and is partly dependent on the prevalence of HLA-B27, which differs in populations with different ethnic backgrounds [1-3].

Osteoporosis in terms of decreased bone mineral density (BMD) is a common complication in AS patients. The prevalence ranges from 19 to $62 \%$ [4-6]. The decrease of BMD can be found both in the hip as well as in the spine and depends on disease duration and presence of syndesmophytes of the spine $[7,8]$. Besides osteoporosis, also vertebral fractures are an important complication of longstanding AS. The prevalence described of known vertebral fractures ranges between 1 and $19 \%$; however, usually most of them remain unrecognized [4, 9-12]. In many cases, neither the patient nor the physician is aware of this increased fracture risk among the relatively young and predominantly male AS population which can result in delay of diagnosis and complications.

Osteoporosis in AS with a long disease duration has been well known for quite some time now [9, 13-17]. Currently, the treatment options for AS have improved since the use of TNF-blocking agents, and the diagnosis is made at an earlier stage of the disease. The knowledge of the prevalence of decreased BMD in this early group, however, is limited despite the fact that a decrease of BMD increases the fracture risk $[8,10,18,19]$. For this reason, we decided to review the literature in order to investigate the prevalence of decreased BMD in patients with AS with a relatively short disease duration $(<10$ years). Secondly, we focused at the clinical relevance of low BMD in this early population, especially in relation with the risk of vertebral fractures, since vertebral fractures are a major and serious cause of morbidity in long-standing AS patients.

\section{Methods}

All patients included in the studies we used for this review had to fulfill the diagnosis of ankylosing spondylitis according to the modified New York criteria [2]. BMD was defined according to the established criteria of the World Health Organization (WHO), which is based on data of postmenopausal women as no criteria of osteopenia and osteoporosis are available for males. Normal bone density was defined as $T$ score $\geq-1.0$, osteopenia as $-2.5<T$ score $<-1.0$, and osteoporosis as $T$ score $\leq-2.5[20,21]$. The $T$ score corresponds to the number of standard deviations (SD) from any result of the peak bone mass. We defined "decreased or low BMD" in this review as $T$ score $\leq-1.0 \mathrm{SD}$, including both osteopenia and osteoporosis.

For this review, disease duration was defined as "time since diagnosis" according to the modified New York criteria [2]. However, in most articles, the definition of disease duration was not available or not clearly described, and when described, in most cases "time since diagnosis" was used as disease duration. Therefore, we decided that disease duration (defined as "time since diagnosis") of less than 10 years was the inclusion criterion for our search, and not symptom duration (defined as "time since first symptoms").

The diagnosis of AS, disease duration of less than 10 years, and the outcome BMD with prevalence numbers were our main inclusion criteria. For this review, we only used BMD data of the articles that were acquired by dual X-ray absorptiometry (DXA), and all other measurements performed were left out. Furthermore, we only used measurements of the lumbar spine and femoral neck. Other measurements will be briefly mentioned.

The databases used were PubMed, MEDLINE, Embase, and Google Scholar with the following free search terms: "ankylosing spondylitis," "osteoporosis," and "bone mineral density." The search in PubMed was also performed with these free terms as MeSH terms. In our search, we always used the Boolean operator "AND." Through Web of Science, we looked at which other articles had quoted our main articles. To expand our search even more, we also used the references mentioned by the articles and reviews we found. Case reports were excluded because they have primarily a signaling function, and extrapolation from their results is not valid.

\section{Statistics}

An analysis was made of the overall prevalence of decreased BMD and for the particular location lumbar spine or femoral neck. This was done by adding up the number of patients having a decreased BMD at that particular location. Subsequently, the total number of patients found with decreased BMD was divided by the total number of patients involved in those articles.

\section{Results}

Search results

A literature search was conducted using the databases and search terms mentioned above. This global search provided us with 35 articles [4, 7-10, 13, 14, 16-19, 22-45]. Using the mentioned inclusion and exclusion criteria, 11 articles were excluded because of an unknown disease duration or disease durations longer than 10 years $[9,14,16,17,34-39$, 44]. Another 16 articles were left out because the prevalence number was not described $[5,8,10,13,18,23,25,28-33$, 40-42]. One article was excluded because it was a case report [43]. One study investigated early SpA patients, but the subgroup of early AS was clearly described and 
therefore also included in this review [19]. This resulted in seven articles which matched all our criteria, and they will be further outlined below (Table 1).

Population

Karberg et al. recruited 103 German AS patients [7]. Dependent on disease duration, they divided their patients into three groups - group 1, patients with disease duration of $<5$ years $(n=27)$; group 2, patients with disease duration of 5-10 years $(n=48)$; and group 3, patients with disease duration $>10$ years $(n=28)$. For our review, we excluded group 3 because of a disease duration of more than 10 years. The study group of Aydin et al. contained 58 Turkish male patients with AS [24]. Two studies were performed in Korea: a study by Baek et al. which included 76 Korean men with AS and a study by Kim et al. which included 60 AS patients [26, 27]. Thirty-nine French white, male patients with AS were included in the study of Dos Santos et al. [22]. In the study of Vasdev et al., 80 Indian male AS patients were studied [45]. The last study included in this review derived from our group by van der Weijden et al. contains 94 Dutch early AS patients [19].

\section{Detection techniques}

All the studies included in this review used DXA to measure BMD. Karberg et al. also used dual-energy quantitative computed tomography and peripheral quantitative computed tomography and compared these results with DXA [7]. Aydin et al. used DXA to measure BMD in the left proximal femur (femoral neck, trochanter area, and total hip), and all scans were analyzed by the same investigator [24]. BMD in the proximal femur was also measured by Baek et al. [27]. They also measured BMD of the lumbar spine (L2-L4). Kim et al. determined BMD at similar places, lumbar spine (L1-L4) and femoral neck [26]. Karberg et al. performed also the same measurements; they measured lumbar spine (L2-L4) and femoral neck, just like van der Weijden et al. [7, 19]. Dos Santos et al. used DXA to measure whole body BMD and regional BMD of the head, arms, whole spine, lumbar spine, pelvis, and legs [22].

\section{Outcome}

The majority of the 482 patients described in the seven studies were male $(87 \%)$, with a mean age of 34.5 years and a mean disease duration of 7.7 years (Table 1). The mean prevalence of low BMD in the early stage of AS was $51 \%$ (range, 16-75\%) for the femoral neck and $54 \%$ (range, 46-74 \%) for the lumbar spine. The mean prevalence of osteopenia for the femoral neck was $38 \%$ (range, $14-56 \%$ ) and $39 \%$ (range, 31-45\%) for the lumbar spine. Osteoporosis was described in 13\% (3-25\%) of the

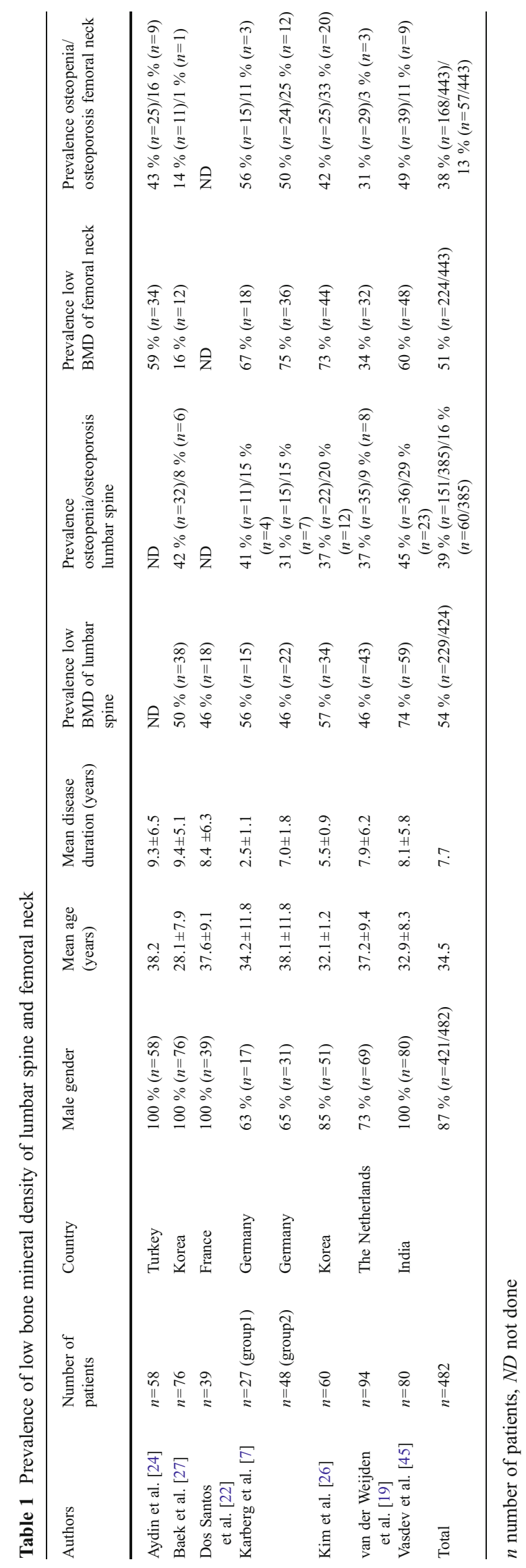


patients at the region of the femoral neck and in $16 \%$ (range, 8-29\%) of the lumbar spine.

Additional numbers were presented by Aydin et al., who also reported low BMD in $57 \%(n=33 / 58)$ of the cases of trochanter and $55 \%(n=32 / 58)$ of total hip [24]. Bone loss was found in 40 patients $(69 \%)$ in at least one of three regions (femoral neck, trochanter, and/or total hip). Overall, $22 \%(n=13)$ had osteoporosis and $47 \%(n=27)$ osteopenia using the WHO criteria for osteoporosis. A lower frequency of decreased BMD of femoral neck and trochanter was found by Baek et al. [27]. The frequency they found was $16 \%(n=12 / 76)$ in femoral neck and $8 \%(n=6 / 76)$ in trochanter. Vasdev et al. also studied BMD in femur trochanter and Ward's triangle [45]. In the femur trochanter, they found $50 \%$ osteopenia and $5 \%$ osteoporosis, and in Ward's triangle, $31 \%$ osteopenia and $2 \%$ osteoporosis.

\section{Description of risk factors of low BMD}

Decreased BMD can occur due to several factors of which old age and female gender are the most important ones. However in early AS, most patients are younger than 40 years of age, and therefore, high age does not seem to be the most important risk factor in this group.

The studies described here dealt differently with the other risk factors of low BMD. Four out of the seven articles excluded patients with common risk factors for osteoporosis, such as use of glucocorticosteroids, hip fractures in the family, and immobilization $[22,24,27]$. Aydin et al. also excluded patients using NSAIDs and DMARDs in the last month, as well as different types of secondary diseases that could cause decreased BMD (i.e., endocrine or metabolic diseases, liver or renal diseases, hip fractures in family, and extremity fractures in the patient). Vasdev et al. and Dos Santos et al. [22, 45] also excluded patients with secondary diseases with the latter also excluding patients with alcohol and tobacco abuse. The remaining studies used no exclusion criteria for their patient selection $[7,19,26]$.

The presence of syndesmophytes in patients included in the articles reviewed could be important since syndesmophytes might falsely increase BMD measured by DXA. Dos Santos et al. therefore excluded patients with syndesmophytes [22]. The others described the percentage of syndesmophytes. Karberg et al. found $26 \%$ syndesmophytes in group $1(n=7)$ and $55 \%$ in group $2(n=26)$, whereas Baek et al. found $36 \%$ syndesmophytes $(n=27)$ [7, 27]. Vasdev et al. reported syndesmophyte formation in $23 \%$ [45] of their patients. Van der Weijden et al. mentioned in their article that only very few patients had a small syndesmophyte which probably could not have influenced their presented results [19]. Aydin et al. and Kim et al. did not mention anything about the presence of syndesmophytes [24, 26].

Another risk factor for osteoporosis is the postmenopausal state of women. Kim et al., Karberg et al., and van der Weijden et al. were the only ones who included women in their studies $[7,19,26]$. The number of women in these studies was low, $15 \%(n=9$, Kim et al.), $37 \%(n=10$, Karberg et al. group 1$)$, $35 \%(n=17$, Karberg et al. group 2$)$, and $27 \%(n=25$, van der Weijden et al.). In the first two studies, menopause was not further pointed out in relation to the reported percentage of decreased bone density. In the study of van der Weijden et al., only two women were postmenopausal, one of them with low BMD and the other with normal BMD. Therefore, female gender does not explain the high prevalence of low BMD in the 482 patients reported in this review.

\section{Discussion}

The literature search for the prevalence of decreased BMD and osteoporosis in AS within the first decade after diagnosis revealed a high mean prevalence of decreased BMD between $51 \%$ of the femoral neck and $54 \%$ of the lumbar spine. Moreover, the prevalence of osteoporosis was $16 \%$ for lumbar spine and $13 \%$ for femoral neck. This corresponds with prevalence numbers found in long-standing AS patients. The variation in prevalence in the studies reviewed is probably mainly caused by differences in the presence or exclusion of cases with risk factors for low BMD between the included patients and the heterogeneity of the populations. However, the fact that the various studies performed within different populations show an almost equally raised prevalence of low BMD strengthens the conclusion that high prevalence of low BMD is already present at the early stages of AS. Obviously, this might be clinically relevant since low BMD is related to an elevated fracture risk in primary osteoporosis in postmenopausal women and men. In line with that, Cooper et al. and Vosse et al. have shown that vertebral fracture risk is elevated in patients with AS $[31,46]$.

Some limitations of this review must be mentioned. Our choice of BMD outcome resulted in exclusion of several articles. We choose to only include studies which gave WHO defined $T$ scores as well as a prevalence to be able to correctly compare and summon BMD outcomes. Also, for decreased BMD, we used the threshold of a $T$ score $<-1.0$, as defined by the WHO. In ISCD 2007, decreased BMD for males younger than 50 years was described as a $T$ score $<-2.0$. However, as all studies used osteopenia $(-2.5<T$ score $<-1.0)$ or osteoporosis $(T$ score $\leq-2.5)$ as BMD outcome measure, we used the osteopenia cutoff point as "low BMD."

The seven studies used for this systematic review were conducted in different countries-Korea [26, 27], France [22], Germany [7], Turkey [24], India [45], and The Netherlands [19]. These countries differ in background risks of osteoporosis due to racial differences, dietary habits, and sun exposure. The differences in prevalence of decreased BMD between areas in a healthy population were shown by Lunt 
et al. They found that BMD of the spine appears to vary in 16 European populations, from 0.934 to $1.0670 \mathrm{~g} / \mathrm{cm}^{2}$ in women and from 1.047 to $1.262 \mathrm{~g} / \mathrm{cm}^{2}$ in men [47-49]. Furthermore, the background prevalence of AS differs among several countries, roughly correlating with the prevalence of HLAB27 $[1,3]$. Beside the genetic factors predisposing to AS, the prevalence of decreased BMD in (early) AS is also influenced by differences in environmental (risk) factors among countries, i.e., vitamin D deficiency, smoking, low body mass index, use of corticosteroids, and anti-TNF alpha therapy [50-54]. Unfortunately, four of the studies reviewed excluded patients with common risk factors for osteoporosis, while the others did not. Besides that, the average participant number of the studies presented was 69 patients which is a relatively small number to extrapolate to a population prevalence $[7,19$, $22,24,26,27,45]$.

Next to general risk factors for low BMD, also diseasespecific risk factors like high disease activity and inflammation are of influence on BMD [9, 13, 55]. Some authors suggest that inflammation can explain the major part of the etiology of decreased BMD with cytokines as interleukin-1 and TNF alpha as primary mediators [18, 23, 56-58], stating that low BMD in AS patients with inflammatory back pain is related to inflammation, whereas Aydin et al. as well as others found that bone loss was related to low serum sex hormone levels in AS [14, 24]. However, Bronson et al. were unable to find a correlation between testosterone levels and decreased BMD [15]. Remarkably, Karberg et al. found that more patients with syndesmophytes had low BMD than those without and therefore suggested that bone loss and bone growth occur parallel, also in early stages of AS [7]. This could not be confirmed by the study of van der Weijden et al. because very few syndesmophytes were found in the early stage of disease in combination with a high prevalence of low BMD (46\%) [19]. In this study, high disease severity indicated by impaired physical function (high BASMI and BASFI levels) and high CRP levels appeared to be strongly associated with low BMD AS within 8 years of onset. So, also in early AS, there seems to be an important role for inflammation [19, 58].

A point worth mentioning regarding this review is the definition of disease duration. In this review, disease duration was defined as the "time since diagnosis." Aydin et al. and van der Weijden et al. both mentioned in their articles the duration from the "moment of diagnosis" and the duration from the "moment of first symptoms" (both $<10$ years) $[19,24]$. Karberg et al., however, defined disease duration as the "time since first symptoms" (also $<10$ years) [7]. Because the definition of Karberg et al. would only have shortened the disease duration (the mean delay between onset of first symptoms and diagnosis can run up to 810 years), this study was considered to be eligible for this review [59-61]. And above that, the results from this study showed already a high prevalence of decreased BMD, which only indicates more that decreased BMD is already present in the (very) early stages of AS.

Another point worth mentioning are the difficulties of diagnosing osteoporosis in AS studies in general. This problem is due to the fact that DXA of lumbar spine has a low sensitivity in detecting decreased BMD in AS patients with a long disease duration due to occurrence of bridging syndesmophytes and ligamentous ossification that might increase the density of the axial skeleton [8, 13, 28, 29]. The studies used in our review reported different percentages of patients with syndesmophytes varying between 7 and $55 \%$ $[7,19,27,45]$, whereas some others excluded patients with syndesmophytes [22], and others did not address the issue of syndesmophytes at all $[24,26]$. The presence of syndesmophytes could have falsely increased the BMD of lumbar spine in these studies, but we found comparable prevalence numbers of low BMD in the hip and spine, so probably the relatively low numbers of syndesmophytes in this early group did not influence the data considerably. But if it did, the real BMD would have been even lower.

Considering the high prevalence of decreased BMD in patients with early AS, the question arises whether or not patients should be treated for this condition. The answer to this question depends on the clinical relevance of this observation. Low BMD becomes clinically relevant when it leads to an increased risk of vertebral and nonvertebral fractures since these fractures are a serious cause of morbidity and reduced quality of life [62-64]. The link between decreased BMD and fracture risk is well known for the general healthy population [65]. In later stages of AS, the risk of vertebral fractures is also significantly increased, and low BMD is an important risk factor for that complication [9, 13-17, 33, 46]. Unfortunately, there is still no consensus whether or not decreased BMD in patients with early AS causes an increased fracture risk [9]. Very few and small studies have been performed in early AS. Jun et al. and van der Weijden et al. found a positive correlation between low BMD and vertebral fractures [25, 66]. Jun et al. found a relation between fractures and femoral BMD, whereas van der Weijden et al. found a relation with BMD of the lumbar spine. Nevertheless, other studies found no correlation with low BMD at all [10, 13].

\section{Conclusion}

These studies show a high prevalence of low BMD (between 51 and $54 \%$ ) and a prevalence of 13-16\% of osteoporosis in AS patients within 10 years after diagnosis. This high prevalence was not to be expected in a relatively young and predominantly male population. No unambiguous correlation between decreased BMD and vertebral fracture risk could be demonstrated; therefore, further research is needed to determine the clinical relevance of low BMD in 
early AS patients by investigating the relation with vertebral and nonvertebral fractures in larger studies.

\section{Disclosures None.}

Open Access This article is distributed under the terms of the Creative Commons Attribution License which permits any use, distribution, and reproduction in any medium, provided the original author(s) and the source are credited.

\section{References}

1. Braun J, Sieper J (2007) Ankylosing spondylitis. Lancet 369:1379-1390

2. van der Linden S, Valkenburg HA, Cats A (1984) Evaluation of diagnostic criteria for ankylosing spondylitis. A proposal for modification of the New York criteria. Arthritis Rheum 27:361-368

3. Khan MA (1996) Epidemiology of HLA-B27 and arthritis. Clin Rheumatol 15(Suppl 1):10-12

4. Bessant R, Keat A (2002) How should clinicians manage osteoporosis in ankylosing spondylitis? J Rheumatol 29:1511-1519

5. Hanson CA, Shagrin JW, Duncan H (1971) Vertebral osteoporosis in ankylosing spondylitis. Clin Orthop Relat Res 74:59-64

6. El Maghraoui A, Borderie D, Cherruau B, Edouard R, Dougados M, Roux C (1999) Osteoporosis, body composition, and bone turnover in ankylosing spondylitis. J Rheumatol 26:2205-2209

7. Karberg K, Zochling J, Sieper J, Felsenberg D, Braun J (2005) Bone loss is detected more frequently in patients with ankylosing spondylitis with syndesmophytes. J Rheumatol 32:1290-1298

8. Mullaji AB, Upadhyay SS, Ho EK (1994) Bone mineral density in ankylosing spondylitis. DEXA comparison of control subjects with mild and advanced cases. J Bone Joint Surg Br 76:660-665

9. Ghozlani I, Ghazi M, Nouijai A, Mounach A, Rezqi A, Achemlal L et al (2009) Prevalence and risk factors of osteoporosis and vertebral fractures in patients with ankylosing spondylitis. Bone 44:772-776

10. Mitra D, Elvins DM, Speden DJ, Collins AJ (2000) The prevalence of vertebral fractures in mild ankylosing spondylitis and their relationship to bone mineral density. Rheumatology (Oxford) 39:85-89

11. Feldtkeller E, Vosse D, Geusens P, van der Linden S (2006) Prevalence and annual incidence of vertebral fractures in patients with ankylosing spondylitis. Rheumatol Int 26:234-239

12. Geusens P, Vosse D, van der Linden S (2007) Osteoporosis and vertebral fractures in ankylosing spondylitis. Curr Opin Rheumatol 19:335-339

13. Donnelly S, Doyle DV, Denton A, Rolfe I, McCloskey EV, Spector TD (1994) Bone mineral density and vertebral compression fracture rates in ankylosing spondylitis. Ann Rheum Dis 53:117-121

14. Franck H, Meurer T, Hofbauer LC (2004) Evaluation of bone mineral density, hormones, biochemical markers of bone metabolism, and osteoprotegerin serum levels in patients with ankylosing spondylitis. J Rheumatol 31:2236-2241

15. Bronson WD, Walker SE, Hillman LS, Keisler D, Hoyt T, Allen SH (1998) Bone mineral density and biochemical markers of bone metabolism in ankylosing spondylitis. J Rheumatol 25:929-935

16. Toussirot E, Michel F, Wendling D (2001) Bone density, ultrasound measurements and body composition in early ankylosing spondylitis. Rheumatology (Oxford) 40:882-888

17. Devogelaer JP, Maldague B, Malghem J, Nagant de Deuxchaisnes C (1992) Appendicular and vertebral bone mass in ankylosing spondylitis. A comparison of plain radiographs with single- and dual-photon absorptiometry and with quantitative computed tomography. Arthritis Rheum 35:1062-1067

18. Gratacos J, Collado A, Pons F, Osaba M, Sanmarti R, Roque M et al (1999) Significant loss of bone mass in patients with early, active ankylosing spondylitis: a followup study. Arthritis Rheum 42:2319-2324

19. van der Weijden MA, van Denderen JC, Lems WF, Heymans MW, Dijkmans BA, van der Horst-Bruinsma IE (2011) Low bone mineral density is related to male gender and decreased functional capacity in early spondylarthropathies. Clin Rheumatol 30 (4):497-503

20. Kanis JA, Melton LJ III, Christiansen C, Johnston CC, Khaltaev N (1994) The diagnosis of osteoporosis. J Bone Miner Res 9:1137-1141

21. (1994) Assessment of fracture risk and its application to screening for postmenopausal osteoporosis. Report of a WHO Study Group. World Health Organ Tech Rep Ser 843:1-129

22. Dos Santos FP, Constantin A, Laroche M, Destombes F, Bernard J, Mazieres B et al (2001) Whole body and regional bone mineral density in ankylosing spondylitis. J Rheumatol 28:547-549

23. Maillefert JF, Aho LS, El MA, Dougados M, Roux C (2001) Changes in bone density in patients with ankylosing spondylitis: a two-year follow-up study. Osteoporos Int 12:605-609

24. Aydin T, Karacan I, Demir SE, Sahin Z (2005) Bone loss in males with ankylosing spondylitis: its relation to sex hormone levels. Clin Endocrinol (Oxf) 63:467-469

25. Jun JB, Joo KB, Her MY, Kim TH, Bae SC, Yoo DH et al (2006) Femoral bone mineral density is associated with vertebral fractures in patients with ankylosing spondylitis: a cross-sectional study. J Rheumatol 33:1637-1641

26. Kim HR, Lee SH, Kim HY (2006) Elevated serum levels of soluble receptor activator of nuclear factors-kappaB ligand (sRANKL) and reduced bone mineral density in patients with ankylosing spondylitis (AS). Rheumatology (Oxford) 45:11971200

27. Baek HJ, Kang SW, Lee YJ, Shin KC, Lee EB, Yoo CD et al (2005) Osteopenia in men with mild and severe ankylosing spondylitis. Rheumatol Int 26:30-34

28. Kaya A, Ozgocmen S, Kamanli A, Ardicoglu O (2009) Bone loss in ankylosing spondylitis: does syndesmophyte formation have an influence on bone density changes? Med Princ Pract 18:470-476

29. El Maghraoui A (2004) Osteoporosis and ankylosing spondylitis. Joint Bone Spine 71:291-295

30. Will R, Palmer R, Bhalla AK, Ring F, Calin A (1989) Osteoporosis in early ankylosing spondylitis: a primary pathological event? Lancet 2:1483-1485

31. Vosse D, Feldtkeller E, Erlendsson J, Geusens P, van der Linden S (2004) Clinical vertebral fractures in patients with ankylosing spondylitis. J Rheumatol 31:1981-1985

32. Vosse D, Landewe R, van der Heijde D, van der Linden S, van Staa TP, Geusens P (2009) Ankylosing spondylitis and the risk of fracture: results from a large primary care-based nested casecontrol study. Ann Rheum Dis 68:1839-1842

33. Ralston SH, Urquhart GD, Brzeski M, Sturrock RD (1990) Prevalence of vertebral compression fractures due to osteoporosis in ankylosing spondylitis. BMJ 300:563-565

34. Sarikaya S, Basaran A, Tekin Y, Ozdolap S, Ortancil O (2007) Is osteoporosis generalized or localized to central skeleton in ankylosing spondylitis? J Clin Rheumatol 13:20-24

35. Incel NA, Gokoglu F, Nacir B, Incel N (2006) Bone and stone in ankylosing spondylitis: osteoporosis and urolithiasis. Clin Rheumatol 25:667-670

36. Capaci K, Hepguler S, Argin M, Tas I (2003) Bone mineral density in mild and advanced ankylosing spondylitis. Yonsei Med J 44:379-384 
37. Speden DJ, Calin AI, Ring FJ, Bhalla AK (2002) Bone mineral density, calcaneal ultrasound, and bone turnover markers in women with ankylosing spondylitis. J Rheumatol 29:516-521

38. Meirelles ES, Borelli A, Camargo OP (1999) Influence of disease activity and chronicity on ankylosing spondylitis bone mass loss. Clin Rheumatol 18:364-368

39. Singh A, Bronson W, Walker SE, Allen SH (1995) Relative value of femoral and lumbar bone mineral density assessments in patients with ankylosing spondylitis. South Med J 88:939-943

40. Henry MJ, Pasco JA, Korn S, Gibson JE, Kotowicz MA, Nicholson GC (2010) Bone mineral density reference ranges for Australian men: Geelong Osteoporosis Study. Osteoporos Int 21:909-917

41. Lee YS, Schlotzhauer T, Ott SM, van Vollenhoven RF, Hunter J, Shapiro J et al (1997) Skeletal status of men with early and late ankylosing spondylitis. Am J Med 103:233-241

42. Park MC, Chung SJ, Park YB, Lee SK (2008) Bone and cartilage turnover markers, bone mineral density, and radiographic damage in men with ankylosing spondylitis. Yonsei Med J 49:288-294

43. Neill TW, Prouse P, Bhalla AK (1994) Ankylosing spondylitis associated with osteoporosis and vertebral deformity. Clin Rheumatol 13:113-114

44. Korkosz M, Gasowski J, Grzanka P, Gorczowski J, Pluskiewicz W, Jeka S et al (2011) Baseline new bone formation does not predict bone loss in ankylosing spondylitis as assessed by quantitative computed tomography (QCT): 10-year follow-up. BMC Musculoskelet Disord 12:121

45. Vasdev V, Bhakuni D, Garg MK, Narayanan K, Jain R, Chadha D (2011) Bone mineral density in young males with ankylosing spondylitis. Int J Rheum Dis 14:68-73

46. Cooper C, Carbone L, Michet CJ, Atkinson EJ, O'Fallon WM, Melton LJ III (1994) Fracture risk in patients with ankylosing spondylitis: a population based study. J Rheumatol 21:1877-1882

47. Lunt M, Felsenberg D, Adams J, Benevolenskaya L, Cannata J, Dequeker J et al (1997) Population-based geographic variations in DXA bone density in Europe: the EVOS Study. European Vertebral Osteoporosis. Osteoporos Int 7:175-189

48. Nguyen HT, von Schoultz B, Pham DM, Nguyen DB, Le QH, Nguyen DV et al (2009) Peak bone mineral density in Vietnamese women. Arch Osteoporos 4:9-15

49. Looker AC, Wahner HW, Dunn WL, Calvo MS, Harris TB, Heyse SP et al (1998) Updated data on proximal femur bone mineral levels of US adults. Osteoporos Int 8:468-489

50. Curtis JR, McClure LA, Delzell E, Howard VJ, Orwoll E, Saag KG et al (2009) Population-based fracture risk assessment and osteoporosis treatment disparities by race and gender. J Gen Intern Med 24:956-962

51. Pinheiro MM, dos Reis Neto ET, Machado FS, Omura F, Yang JH, Szejnfeld J et al (2010) Risk factors for osteoporotic fractures and low bone density in pre and postmenopausal women. Rev Saude Publica 44:479-485
52. Mithal A, Wahl DA, Bonjour JP, Burckhardt P, wson-Hughes B, Eisman JA et al (2009) Global vitamin D status and determinants of hypovitaminosis D. Osteoporos Int 20:1807-1820

53. Caplan L, Saag KG (2009) Glucocorticoids and the risk of osteoporosis. Expert Opin Drug Saf 8:33-47

54. Briot K, Gossec L, Kolta S, Dougados M, Roux C (2008) Prospective assessment of body weight, body composition, and bone density changes in patients with spondyloarthropathy receiving anti-tumor necrosis factor-alpha treatment. J Rheumatol $35: 855-861$

55. Mermerci BB, Pekin DY, Sivas F, Bodur H, Ozoran K (2010) The relation between osteoporosis and vitamin $\mathrm{D}$ levels and disease activity in ankylosing spondylitis. Rheumatol Int 30:375-381

56. Gowen M, Mundy GR (1986) Actions of recombinant interleukin 1 , interleukin 2, and interferon-gamma on bone resorption in vitro. J Immunol 136:2478-2482

57. Lange U, Teichmann J, Stracke H (2000) Correlation between plasma TNF-alpha, IGF-1, biochemical markers of bone metabolism, markers of inflammation/disease activity, and clinical manifestations in ankylosing spondylitis. Eur J Med Res 5:507-511

58. Haugeberg G, Bennett AN, McGonagle D, Emery P, Marzo-Ortega $\mathrm{H}$ (2010) Bone loss in very early inflammatory back pain in undifferentiated spondyloarthropathy: a 1-year observational study. Ann Rheum Dis 69:1364-1366

59. Dincer U, Cakar E, Kiralp MZ, Dursun H (2008) Diagnosis delay in patients with ankylosing spondylitis: possible reasons and proposals for new diagnostic criteria. Clin Rheumatol 27:457-462

60. Feldtkeller E, Erlendsson J (2008) Definition of disease duration in ankylosing spondylitis. Rheumatol Int 28:693-696

61. Feldtkeller E, Khan MA, van der Heijde D, van der Linden S, Braun J (2003) Age at disease onset and diagnosis delay in HLA-B27 negative vs. positive patients with ankylosing spondylitis. Rheumatol Int 23:61-66

62. Suzuki N, Ogikubo O, Hansson T (2008) The course of the acute vertebral body fragility fracture: its effect on pain, disability and quality of life during 12 months. Eur Spine J 17:1380-1390

63. Wasnich RD, Ross PD, Davis JW, Vogel JM (1989) A comparison of single and multi-site BMC measurements for assessment of spine fracture probability. J Nucl Med 30:1166-1171

64. Cummings SR, Black DM, Nevitt MC, Browner W, Cauley J, Ensrud K et al (1993) Bone density at various sites for prediction of hip fractures. The Study of Osteoporotic Fractures Research Group. Lancet 341:72-75

65. Melton LJ III, Atkinson EJ, O'Connor MK, O'Fallon WM, Riggs BL (1998) Bone density and fracture risk in men. J Bone Miner Res 13:1915-1923

66. van der Weijden MA, van der Horst-Bruinsma IE, van Denderen JC, Dijkmans BA, Heymans MW, Lems WF (2012) High frequency of vertebral fractures in early spondylarthropathies. Osteoporos Int 23(6):1683-90 